\title{
Exercise as a tool for hypertension and resistant hypertension management: current insights
}

This article was published in the following Dove Press journal: Integrated Blood Pressure Control

\author{
Susana Lopes ${ }^{1,2}$ \\ José Mesquita-Bastos ${ }^{1,3}$ \\ Alberto J Alves ${ }^{4}$ \\ Fernando Ribeiro ${ }^{1,2}$ \\ 'School of Health Sciences, \\ University of Aveiro, Aveiro, Portugal; \\ ${ }^{2}$ Institute of Biomedicine - iBiMED, \\ University of Aveiro, Aveiro, Portugal; \\ ${ }^{3}$ Cardiology Department, Hospital \\ Infante D. Pedro, Centro Hospitalar \\ do Baixo Vouga, Aveiro, Portugal; \\ ${ }^{4}$ Research Center in Sports Sciences, \\ Health and Human Development, \\ CIDESD, University Institute of Maia, \\ Maia, Portugal
}

\begin{abstract}
Although there has been an observed progress in the treatment of hypertension, its prevalence remains elevated and constitutes a leading cause of cardiovascular disease development. Resistant hypertension is a challenge for clinicians, as the available treatment options have reduced success. Physical activity and exercise training play an important role in the management of blood pressure. The importance of physical activity and exercise training as part of a comprehensive lifestyle intervention is acknowledged by several professional organizations in their recommendations/guidelines for the management of arterial hypertension. Aerobic exercise, dynamic resistance exercise, and concurrent training - the combination of dynamic resistance and aerobic exercise training in the same exercise session or on separate days - has been demonstrated to reduce blood pressure and help in the management of hypertension. The present review draws attention to the importance of exercise training in the management of blood pressure in both hypertension and resistant hypertension individuals.
\end{abstract}

Keywords: resistant hypertension, exercise capacity, physical activity, lifestyle

\section{Introduction}

Arterial hypertension is the main attributable risk factor for cardiovascular disease. ${ }^{1}$ According to the European Society of Hypertension and European Society of Cardiology Guidelines, ${ }^{2}$ hypertension is defined as an office SBP of $\geq 140 \mathrm{mmHg}$ and/ or DBP of $\geq 90 \mathrm{mmHg}$ in adults, whereas different criteria, based on percentiles, are adopted in children and teenagers. ${ }^{1,2}$ These blood pressure values should be based on an average of $\geq 2$ careful readings (spaced 1-2 minutes apart) obtained on $\geq 2$ occasions. ${ }^{3}$ Although the definition is based on office blood pressure measurements, in some specific cases (eg, white coat syndrome, masked hypertension, and nocturnal systolic hypertension), the diagnosis of hypertension should be confirmed with out-of-office measurements. ${ }^{1,3}$ Twenty-four-hour ambulatory blood pressure monitoring (ABPM) is generally accepted as the best out-of-office measurement method in terms of diagnosis and cardiovascular prognosis, ${ }^{4,5}$ as it provides more information about the circadian variation during the nighttime period. ${ }^{6}$

The number of people with hypertension has been increasing worldwide dramatically; from 1980 to 2008, the number of adults with hypertension rose from 600 million to 1 billion, representing $\sim 40 \%$ of adults aged 25 years and above. ${ }^{7}$ The 2017 Cardiovascular Disease Statistics ${ }^{8}$ showed that the prevalence of hypertension in the European Society of Cardiology Country members ranged from $15.2 \%$ to $31.7 \%$. The global sex-adjusted prevalence of hypertension was $20.2 \%$ for women and $28.4 \%$ for
Correspondence: Fernando Ribeiro School of Health Sciences, University of Aveiro, Building 30, Agras do Crasto, Campus Universitário de Santiago, 3810193 Aveiro, Portugal Email fernando.ribeiro@ua.pt 
men. ${ }^{8}$ The age-standardized prevalence in women and men was slightly higher in the middle-income countries $(23.5 \%$ and $30.3 \%$ ) than in the high-income countries $(18.3 \%$ and $27.3 \%){ }^{8}$

Hypertension is frequently concomitant with other pathologies. For instance, obesity-associated hypertension is the most common hypertension phenotype among adolescents; approximately $30 \%$ of obese adolescents have elevated blood pressure or hypertension. ${ }^{9}$ The great majority of the population with hypertension has also additional cardiovascular risk factors, which may potentiate each other and increase the total cardiovascular risk. ${ }^{1}$ Some particular groups of hypertensive patients imply special care. One of the most difficult groups to control blood pressure values are patients with resistant hypertension. These patients are poorly responsive to treatment and require the use of multiple medications. The definition of resistant hypertension is an uncontrolled arterial blood pressure with three antihypertensive drugs in adequate doses including a diuretic, or controlled with four or more antihypertensive agents. ${ }^{1,10,11}$ Resistant hypertension is associated with an increased risk of cardiovascular events, including myocardial infarction, stroke, congestive heart failure, and chronic kidney disease. ${ }^{12} \mathrm{~A}$ large epidemiological study found a $50 \%$ increase in cardiovascular events and a twofold increase in overall cardiovascular risk in patients with resistant hypertension as compared to those with non-resistant hypertension. ${ }^{13}$

Numerous antihypertensive medications and combinations are available to control the blood pressure of patients with hypertension; nonetheless, only a small fraction of them achieve the target blood pressure level. ${ }^{14} \mathrm{~A}$ major factor for this observation is that lifestyle-related factors are the only determinants of hypertension that are actually modifiable. ${ }^{15}$ Therefore, it is without surprise that the recommendations for the management of hypertension encourage lifestyle modification (exercise training, smoking cessation, weight loss, healthy eating, and reduced sodium intake) as part of the antihypertensive treatment. ${ }^{1}$ The present review draws attention only to the importance of exercise training in the management of blood pressure.

\section{The antihypertensive effects of exercise in arterial hypertension}

The importance of physical activity and exercise training, as part of a comprehensive lifestyle modification, to reduce blood pressure in adults with arterial hypertension is widely acknowledged in international guidelines. ${ }^{1,3}$ There is a considerable amount of evidence coming from numerous randomized controlled trials assessing the antihypertensive effects of exercise, namely aerobic exercise, and many metaanalyses of these studies supporting the antihypertensive effects of different types of exercise for reducing blood pressure in adults with arterial hypertension. However, the effects of exercise training may change with different exercise modalities and dose parameters. Other exercise modalities, such as isometric exercise and high-intensity interval training, are emerging and gaining the attention of researchers and clinicians. It is important to emphasize that the decrease in blood pressure is one of the many benefits of exercise. Among the benefits of exercise training are the amelioration of traditional cardiovascular risk factors, the increase of cardiorespiratory capacity, myocardial and peripheral perfusion, arterial stiffness, autonomic function, as well as the improvement of the endothelial function and repair, and the decrease of low-grade vascular wall inflammation. ${ }^{16-23}$ The following sections summarize (Table 1) the evidence about the antihypertensive effects of different exercise modalities.

\section{Aerobic exercise training}

There is a general consensus that aerobic exercise training reduces SBP and DBP of hypertensive patients; a meta-analysis of randomized controlled trials lasting $\geq 4$ weeks concluded that aerobic exercise significantly decreases office SBP $(-8.3$ [range -10.7 to -6.0 ] $\mathrm{mmHg})$ and DBP $(-5.2$ [range -6.9 to $-3.4] \mathrm{mmHg}$ ) in hypertensive patients. ${ }^{24}$ The magnitude of the decrease was higher in patients with hypertension compared to patients with prehypertension (systolic, -4.3 [range -7.7 to -0.9 ]; diastolic, -1.7 [range -2.7 to -0.7 ] $\mathrm{mmHg}$ ) or normal blood pressure (systolic, -0.75 [range -2.2 to +0.7 ]; diastolic, -1.1 [range -2.2 to -0.1 ] $\mathrm{mmHg}){ }^{24} \mathrm{~A}$ recent review of 27 randomized controlled trials, a total of 1,480 participants, expanded on the effects of aerobic exercise for lowering blood pressure in participants with hypertension and observed a mean reduction of $10.8 / 4.7 \mathrm{mmHg}$ for $\mathrm{SBP} / \mathrm{DBP}$, in the included trials with $3+$ level of evidence. ${ }^{14}$ Likewise, the results of a meta-analysis of 15 randomized controlled trials of at least 4 weeks investigating the effects of aerobic training on ambulatory blood pressure in adults with hypertension showed a significant reduction of 3.8 and $3.0 \mathrm{mmHg}$ for daytime systolic and diastolic ambulatory blood pressure, respectively. ${ }^{25}$

\section{Resistance exercise training}

Regarding dynamic resistance exercise, a recent metaanalysis analyzed 64 controlled studies, involving a total of 2,344 adults with high blood pressure, of which $15 \%$ were on antihypertensive medication, to determine whether dynamic resistance exercise is an effective stand-alone 
Table I Summary of the main systematic reviews with meta-analysis covering the effects of exercise training on blood pressure control

\begin{tabular}{|c|c|c|}
\hline Author, date & Main characteristics of the review & Main results \\
\hline \multicolumn{3}{|c|}{ Aerobic exercise training } \\
\hline Börjesson et al, 2016 14 & 27 RCTs, with a total of I,480 participants & $\begin{array}{l}\text { Mean reductions of } 10.8 \mathrm{mmHg} \text { for } \mathrm{SBP} \text { and } 4.7 \mathrm{mmHg} \text { for } \mathrm{DBP} \text {; } \\
40-60 \text { minutes/session, } \geq 3 \text { times/week, } \geq 4 \text { weeks, at moderate or } \\
\text { high intensity was associated with the greatest } \mathrm{BP} \text { lowering effect }\end{array}$ \\
\hline Cornelissen et al, $2013^{16}$ & $\begin{array}{l}\text { I5 RCTs, with } 633 \text { participants } \\
30-60 \text { minutes/session, } 2-5 \text { times/week, } \geq 4 \text { weeks } \\
\text { (6-52 weeks), at } 50 \%-75 \% \text { HR reserve }\end{array}$ & $\begin{array}{l}\text { Reduction in daytime SBP and DBP: } 3.2 \mathrm{mmHg} \text { and } 2.7 \mathrm{mmHg} \\
\text { No nighttime BP reduction }\end{array}$ \\
\hline Cornelissen et al, $2013^{17}$ & $\begin{array}{l}59 \text { RCTs, with 3,957 participants } \\
30-60 \text { minutes/session, 3-5 times/week, 4-52 } \\
\text { weeks, at moderate intensity (walking and jogging) }\end{array}$ & $\begin{array}{l}\text { Office } \mathrm{SBP} \text { and DBP reduction of } 8.3 \text { and } 5.2 \mathrm{mmHg} \text {, respectively, } \\
\text { in hypertensive participants; } 4.3 \text { and } 1.7 \mathrm{mmHg} \text { in prehypertensive, } \\
\text { and } 0.75 \text { and } 1.1 \mathrm{mmHg} \text { in normotensive participants }\end{array}$ \\
\hline \multicolumn{3}{|c|}{ Resistance exercise training } \\
\hline MacDonald et al, $2016^{18}$ & $\begin{array}{l}64 \text { controlled studies, with } 2,344 \text { participants } \\
\text { Moderate-intensity resistance exercise, mean } 65 \% \\
\text { I-RM; } 3 \text { sets, } 8 \text { exercises, II repetitions; } 3 \text { times/ } \\
\text { week, 6-48 weeks }\end{array}$ & $\begin{array}{l}\text { Reductions of SBP and DBP of } 5.7 / 5.2 \mathrm{mmHg} \text { in participants } \\
\text { with hypertension and } 3.0 / 3.3 \mathrm{mmHg} \text { in participants with } \\
\text { prehypertension }\end{array}$ \\
\hline \multicolumn{3}{|c|}{ Concurrent exercise training } \\
\hline Corso et al, $2016^{20}$ & $\begin{array}{l}68 \text { trials, with } 4,110 \text { participants } \\
60 \text { minutes/session; } 3 \text { times/week, } 3-144 \text { weeks of } \\
\text { moderate intensity (aerobic exercise at } 55 \% \mathrm{VO}_{2} \\
\text { max; resistance exercise at } 60 \% \text { I-RM) }\end{array}$ & $\begin{array}{l}\text { Reductions of SBP and DBP of } 5.3 / 5.6 \mathrm{mmHg} \text { in hypertensive } \\
\text { patients and } 2.9 / 3.6 \mathrm{mmHg} \text { in prehypertension. Reductions } \\
\text { of } 9 / 7.7 \mathrm{mmHg} \text { were found in higher quality studies with } \\
\text { hypertensive participants }\end{array}$ \\
\hline \multicolumn{3}{|c|}{ Isometric exercise training } \\
\hline Inder et al, $2016^{21}$ & $\begin{array}{l}\text { II RCTs, with } 302 \text { participants; } 6 \text { trials used } \\
\text { handgrip and } 5 \text { used leg exercises }\end{array}$ & $\begin{array}{l}\text { Decrease in SBP }(4.5 \mathrm{mmHg}) \text { and } \mathrm{DBP}(4.5 \mathrm{mmHg}) \text { in hypertensive } \\
\text { participants } \\
\text { Higher SBP decrease in handgrip }(6.9 \mathrm{mmHg}) \text { vs leg exercise }(4.2 \\
\mathrm{mmHg})\end{array}$ \\
\hline Jin et al, $2017^{22}$ & 6 RCTs, with 157 subjects & $\begin{array}{l}\text { Reductions of SBP and DBP of } 8.33 \text { and } 3.9 \mathrm{mmHg} \text { in hypertensive } \\
\text { patients }\end{array}$ \\
\hline
\end{tabular}

Abbreviations: RCT, randomized controlled trials; RM, repetition maximum.

antihypertensive therapy. ${ }^{26}$ In general, the exercise protocol included 2.8 \pm 0.6 sessions of moderate-intensity resistance exercise per week during 6-48 weeks. The overall reductions in SBP and DBP were -0.4 and $-0.4 \mathrm{mmHg}$, respectively. However, larger blood pressure reductions occurred in participants with higher resting SBP/DBP, ie, 5.7/5.2 $\mathrm{mmHg}$ in participants with hypertension and $3.0 / 3.3 \mathrm{mmHg}$ in participants with prehypertension. The greater reductions in SBP were observed in those studies performing eight or more resistance exercises per session compared to the studies using less than eight exercises per session (4.4 vs $1.4 \mathrm{mmHg}, P=0.043$ ); interestingly, the reduction in SBP was increased when those performing eight or more exercises per session were adults with untreated hypertension $(-11.8 \mathrm{mmHg}, 95 \% \mathrm{CI}-16.0$ to -7.4$)$. The greater reductions in DBP were achieved also in adults with untreated hypertension, but when performing three or more dynamic resistance exercise sessions per week $(-9.9 \mathrm{mmHg}, 95 \% \mathrm{CI}-13.9$ to -5.9$)$.

\section{Concurrent exercise training}

Concurrent training, ie, the combination of dynamic resistance and aerobic exercise training in the same exercise session or on separate days, is an exercise modality recommended by the American College of Sports Medicine (ACSM) for adults with high blood pressure. ${ }^{27}$ ACSM recommends at least 30 minutes of moderate aerobic exercise ( $40 \%-60 \% \mathrm{VO}_{2}$ reserve) on most, preferably all, days of the week, supplemented by moderate resistance exercise ( $60 \%-80 \%$ of one-repetition maximum), $8-12$ repetitions, 2-3 days per week. ${ }^{27}$ A recent meta-analyses of 68 trials which focused exclusively on adults with hypertension supports the efficacy of concurrent training as antihypertensive therapy. ${ }^{28}$ In general, the studies employed concurrent training for $2.9 \pm 0.7$ days per week at moderate intensity (aerobic exercise at $55 \% \mathrm{VO}_{2}$ max; dynamic resistance exercise at $60 \%$ of one-repetition maximum) in sessions lasting $\sim 1$ hour (58.3 \pm 20.1 minutes) for 3-144 weeks. The majority of them performed aerobic and resistance exercise on the same day (aerobic first or resistance first or circuit training alternating aerobic and resistance) and only a small percentage of studies did aerobic and resistance exercise sessions on separate days. Collectively, the studies showed a reduction of $5.3 \mathrm{mmHg}$ and $2.9 \mathrm{mmHg}$ in SBP and $5.6 \mathrm{mmHg}$ and $3.6 \mathrm{mmHg}$ in DBP of participants with hypertension and 
prehypertension, respectivelly. ${ }^{28}$ The greatest systolic $(9.2$ $\mathrm{mmHg}, 95 \%$ CI $12.0-8.2)$ and diastolic $(7.7 \mathrm{mmHg}, 95 \%$ CI 14.0-8.3) blood pressure reductions were observed in participants with hypertension in higher-quality trials that examined blood pressure as a primary outcome. ${ }^{28}$ Interestingly, these results were not changed by the order or proximity of the aerobic and resistance exercise components. A previous meta-analysis, reporting a wide variation in the blood pressure reductions (ranging from -21 to $+1 \mathrm{mmHg}$ for SBP and -14 to $+6 \mathrm{mmHg}$ for DBP), also showed that studies with higher methodological quality obtained larger blood pressure reductions in comparison to lower methodological quality trials. ${ }^{24}$

\section{Isometric exercise training}

Isometric exercise, ie, when a muscle develops tension with no visible or external change in joint position, has been studied as an alternative to those hypertensive patients that cannot perform or do not adhere to the conventional aerobic or resistance exercise programs. Recent data suggest isometric exercise as a new non-pharmacological therapeutic tool to lower blood pressure; two recent meta-analyse ${ }^{29,30}$ quantified the effects of isometric resistance training on the change in blood pressure in adults and observed reductions in systolic, diastolic, and mean blood pressure. Inder et $\mathrm{al}^{29}$ reviewed eleven randomized trials, totaling 302 participants; six studies used handgrip and five used leg exercise and reported an overall decrease in SBP of $5.2 \mathrm{mmHg}$ and DBP of $3.9 \mathrm{mmHg}$. Notably, only three studies out of eleven, totaling 61 participants, enrolled hypertensive adults. In these studies, the overall decrease in systolic, diastolic, and mean blood pressure was 4.5, 4.5, and $5.9 \mathrm{mmHg}$, respectively. Interestingly, the studies using arm isometric resistance exercise (6.9 $\mathrm{mmHg}, 95 \%$ CI 8.3-5.5) showed a higher decrease in SBP than those using lower limb isometric resistance exercise (4.2 $\mathrm{mmHg}, 95 \%$ CI 5.3-3.1). Also, unilateral isometric resistance exercise $(8.9 \mathrm{mmHg}, 95 \%$ CI 11.2-6.6) was superior to bilateral exercise $(4.6 \mathrm{mmHg}$, $95 \%$ CI 5.5-3.6) in reducing SBP. Older adults ( $\geq 45$ years of age) showed larger reductions in mean blood pressure (5.5 mmHg, 95\% CI 6.9-4.1) than those below 45 years. The duration of the program also modulates the reduction of systolic and mean blood pressure, with longer programs ( $\geq 8$ weeks) inducing higher reductions (systolic, $7.3 \mathrm{mmHg}, 95 \%$ CI 8.5-6.0; mean pressure, $4.2 \mathrm{mmHg}, 95 \%$ CI 5.1-3.4). ${ }^{29}$

It is interesting to note that the involvement of smaller muslce mass during isometric exercise (unilateral vs bilateral and upper limb vs lower limb) resulted in higher decreases in blood pressure. Nonetheless, the reduced number of studies conducted in hypertensive adults, together with the neutral results observed in a recent randomized controlled trial comparing the antihypertensive effects of an acute bout of aerobic with those elicited by isometric handgrip resistance exercise, ${ }^{31}$ clearly establish the need for more research to confirm the potential benefits of isometric resistance exercise in reducing high blood pressure.

\section{Exercise for the management of resistant hypertension}

Aerobic exercise training has proven to decrease SBP and DBP in hypertensive patients ${ }^{32}$ and is broadly recommended by international guidelines. ${ }^{1,33}$ However, guidelines lack recommendations regarding exercise for patients with resistant hypertension. Regular physical activity is associated with reduced risk for mortality and cardiovascular events in treatment-resistant hypertension. ${ }^{34}$ Even though evidence for the benefits of physical exercise is still scarce for resistant hypertensive patients, few studies have been conducted with promising outcomes. An 8-12-week aerobic exercise program $^{35}$ that consisted of walking on a treadmill according to an interval-training pattern, three times per week, decreased 24-hour systolic ABPM by $5.4 \pm 12.2 \mathrm{mmHg}$ and 24-hour diastolic ABPM by $2.8 \pm 5.9 \mathrm{mmHg}$. Daytime systolic and diastolic ABPM decreased by $5.9 \pm 11.6 \mathrm{mmHg}$ and $3.3 \pm 6.5$ $\mathrm{mmHg}$ and nighttime systolic and diastolic ABPM decreased by $3.8 \pm 17.1 \mathrm{mmHg}$ and $1.9 \pm 8.2 \mathrm{mmHg}$, respectively. ${ }^{35}$ This downward trend in ABPM was also observed in subsequent studies with heated water-based exercise training. ${ }^{36-38} \mathrm{~A}$ 12-week heated water-based exercise training ${ }^{37}$ composed of 60-minute exercise sessions of callisthenic exercises against water resistance and walking, three times per week, decreased systolic and diastolic ABPM, respectively, in the 24-hour period by $19.5 \pm 11.0 \mathrm{mmHg}$ and $11.1 \pm 3.1 \mathrm{mmHg}$, daytime by $22.3 \pm 12.6 \mathrm{mmHg}$ and $13.0 \pm 3.6 \mathrm{mmHg}$, and nighttime by $17.4 \pm 9.1 \mathrm{mmHg}$ and $8.5 \pm 2.1 \mathrm{mmHg}$. The authors associated the greater magnitude of the blood pressure reductions, compared with the land-based exercise program, ${ }^{35}$ with the immersion in water at a temperature of $30^{\circ} \mathrm{C}-32^{\circ} \mathrm{C}$. A previous short-term heated water-based exercise training of 2 weeks by the same group had led to a decrease of systolic and diastolic ABPM, respectively, in the 24-hour period (-11.6/$8.4 \mathrm{mmHg})$, daytime $(-11.6 /-6.4 \mathrm{mmHg})$, and nighttime $(-9.6 /-7.4 \mathrm{mmHg}){ }^{36}$ The magnitude of these reductions in the ABPM levels was found to be even higher for patients with resistant hypertension than for those with hypertension. ${ }^{24,27}$ This could be associated with the fact that higher baseline blood pressure measures allow greater reduction with exercise. 
Recently, the post-exercise hypotension phenomenon, ie, a transient reduction in blood pressure in the period after exercise to values less than those observed before exercise, ${ }^{39}$ was studied in patients with resistant hypertension. The clinical utility of this temporary decrease in blood pressure is related to the decreased cardiac afterload during the period of time subsequent to the exercise. A single exercise session elicits this phenomenon in middle-aged, ${ }^{40,41}$ elderly, ${ }^{42,43}$ and very old individuals with hypertension..$^{44}$ This was recently addressed in 20 patients with resistant hypertension, in whom the acute hemodynamic effects of 45 minutes of lightand moderate-intensity aerobic exercise $(50 \%$ and $75 \%$ of maximum heart rate and mean rate of perceived exertion of $11.7 \pm 0.4$ and $14.0 \pm 0.2$ [Borg scale], respectively) were assessed ${ }^{45}$ Both exercise intensities reduced the systolic ABPM over 5 hours (light: $-7.7 \pm 2.4 \mathrm{mmHg}$ and moderate: $-9.4 \pm 2.8 \mathrm{mmHg}$ ), compared to controls; however, only light-intensity exercise reduced diastolic ABPM $(-5.7 \pm 2.2$ $\mathrm{mmHg}$ ). Systolic and diastolic ABPM were also lowered, with light-intensity exercise, over 10 hours during daytime $(-3.8 \pm 1.3$ and $-4.0 \pm 1.3 \mathrm{mmHg}$, respectively) and nighttime $(-6.0 \pm 2.4$ and $-6.1 \pm 1.6 \mathrm{mmHg}$, respectively), and diastolic ABPM over 19 hours $(-4.8 \pm 1.2 \mathrm{mmHg})$. The authors found that both light- and moderate-intensity aerobic exercise elicit transient reductions in ambulatory blood pressure of patients with resistant hypertension. However, light intensity seems to sustain longer effects. ${ }^{45}$ These results are contrary to other studies where higher intensities elicited greater post-exercise hypotension..$^{27,46}$ However, a review by Anunciação et $\mathrm{al}^{47}$ noted that although some studies showed that high-intensity exercises $\left(70 \%-75 \% \mathrm{VO}_{2} \max \right)$ promote greater reductions in blood pressure values than mild-intensity $\left(50 \% \mathrm{VO}_{2} \max \right)$ activities, others have reported no differences in blood pressure between different exercise intensities.

Taken together, these findings suggest a potential role for exercise in the management of blood pressure in these patients. However, none of the referred studies provide a follow-up evaluation to clarify whether the effects of exercise could be maintained. Further investigation is required to increase the validity of the existing evidence, and to clarify the pathways underlying the exercise-induced blood pressure decrease in patients with resistant hypertension.

\section{Summary}

The prevalence of arterial hypertension is still elevated worldwide, and is a major risk factor for the development of cardiovascular diseases. Regular exercise reduces the blood pressure of individuals with hypertension. The present understanding indicates that aerobic exercise training, dynamic resistance exercise, and concurrent training are effective antihypertensive therapies. The potential benefit of isometric exercise in reducing high blood pressure, especially in those adults lacking capacity to perform any other form of exercise, needs to be clearly confirmed in future randomized controlled trials.

Resistant hypertension is a medical problem without a clear solution, since antihypertensive medications and renal denervation - the common treatment options to lower blood pressure in these patients - have demonstrated reduced efficacy. ${ }^{48,49}$ Recently, aerobic exercise training has been recognized as a promising therapeutic tool to reduce blood pressure in resistant hypertension; the blood pressure reduction observed in patients with resistant hypertension following an aerobic exercise training program is promising, but must be confirmed in larger randomized controlled studies.

\section{Acknowledgments}

This work is financed by FEDER funds through the Operational Competitiveness Factors Program - COMPETE and by National Funds through FCT - Foundation for Science and Technology within the project "P2020-PTDC/DTPDES/1725/2014." iBiMED is a research unit supported by the Portuguese Foundation for Science and Technology (FCT) (Ref: UID/BIM/04501/2013) and POCI-01-0145FEDER-007628 funds. CIDESD is a research unit supported by FCT (UID/DTP/04045/2013) and by the European Regional Development Fund, through COMPETE 2020 (POCI-01-0145-FEDER-006969). Susana Lopes received a $\mathrm{PhD}$ grant from the Foundation for Science and Technology (SFRH/BD/129454/2017).

\section{Disclosure}

The authors report no conflicts of interest in this work.

\section{References}

1. Mancia G, Fagard R, Narkiewicz K, ESH/ESC Task Force for the Management of Arterial Hypertension. 2013 Practice guidelines for the management of arterial hypertension of the European Society of Hypertension (ESH) and the European Society of Cardiology (ESC): ESH/ESC Task Force for the Management of Arterial Hypertension. J Hypertens. 2013;31(10):1925-1928.

2. Chobanian AV, Bakris GL, Black HR, et al. The Seventh Report of the Joint National Committee on Prevention, Detection, Evaluation, and Treatment of High Blood Pressure: the JNC 7 report. JAMA. 2003;289(19):2560.

3. Whelton PK, Carey RM, Aronow WS, et al. ACC/AHA/AAPA/ABC/ ACPM/AGS/APhA/ASH/ASPC/NMA/PCNA Guideline for the Prevention, Detection, Evaluation, and Management of High Blood Pressure in Adults. J Am Coll Cardiol. 2017;2017(17):735-1097.

4. Bastos JM, Bertoquini S, Polónia J. Prognostic value of subdivisions of nighttime blood pressure fall in hypertensives followed up for 8.2 years. Does nondipping classification need to be redefined? J Clin Hypertens. 2010;12(7):508-515. 
5. Staessen JA, Li Y, Hara A, Asayama K, Dolan E, O'Brien E. Blood Pressure Measurement Anno 2016. Am J Hypertens. 2017;30(5):453-463.

6. Braam B, Taler SJ, Rahman M, et al. Recognition and Management of Resistant Hypertension. Clin J Am Soc Nephrol. 2017;12(3): 524-535.

7. World Health Organization. Global Status Report on Noncommunicable Diseases 2010. Available from: http://apps.who.int/iris/bitstream/ handle/10665/44579/9789240686458_eng.pdf;jsessionid=486689EF6F D464B61B093A62DCBC6A6F? sequence=1. Accessed December 23, 2017.

8. Timmis A, Townsend N, Gale C, et al. European Society of Cardiology: Cardiovascular Disease Statistics 2017. Eur Heart J. 2017:1-72.

9. Falkner B. Monitoring and management of hypertension with obesity in adolescents. Integr Blood Press Control. 2017;10:33-39.

10. Kumar N, Calhoun DA, Dudenbostel T. Management of patients with resistant hypertension: current treatment options. Integr Blood Press Control. 2013;6:139.

11. Vemulapalli S, Ard J, Bakris GL, et al. Proceedings from Duke resistant hypertension think tank. Am Heart J. 2014;167(6):775-788.

12. Feldman RD, Brass EP. From bad behaviour to bad biology: pitfalls and promises in the management of resistant hypertension. Can J Cardiol. 2013;29(5):549-556.

13. Vongpatanasin W. Resistant hypertension: a review of diagnosis and management. JAMA. 2014;311(21):2216-2224.

14. Börjesson M, Onerup A, Lundqvist S, Dahlöf B. Physical activity and exercise lower blood pressure in individuals with hypertension: narrative review of 27 RCTs. Br J Sports Med. 2016;50(6):356-361.

15. Egan BM, Li J, Hutchison FN, Ferdinand KC. Hypertension in the United States, 1999 to 2012: progress toward Healthy People 2020 goals. Circulation. 2014;130(19):1692-1699.

16. Gielen S, Schuler G, Hambrecht R. Exercise training in coronary artery disease and coronary vasomotion. Circulation. 2001;103(1):e1-e6.

17. Lavie CJ, Milani RV. Cardiac rehabilitation and exercise training in secondary coronary heart disease prevention. Prog Cardiovasc Dis. 2011;53(6):397-403.

18. Linke A, Erbs S, Hambrecht R. Exercise and the coronary circulationalterations and adaptations in coronary artery disease. Prog Cardiovasc Dis. 2006;48(4):270-284.

19. Möbius-Winkler S, Uhlemann M, Adams V, et al. Coronary Collateral Growth Induced by Physical Exercise clinical perspective. Circulation. 2016;133(15):1438-1448

20. O'Connor CM, Whellan DJ, Lee KL, et al. Efficacy and Safety of Exercise Training in Patients With Chronic Heart Failure. JAMA. 2009;301(14):1439.

21. Pearson MJ, Mungovan SF, Smart NA. Effect of exercise on diastolic function in heart failure patients: a systematic review and meta-analysis. Heart Fail Rev. 2017;22(2):229-242.

22. Ribeiro F, Alves AJ, Duarte JA, Oliveira J. Is exercise training an effective therapy targeting endothelial dysfunction and vascular wall inflammation? Int J Cardiol. 2010;141(3):214-221.

23. Ribeiro F, Ribeiro IP, Alves AJ, et al. Effects of exercise training on endothelial progenitor cells in cardiovascular disease: a systematic review. Am J Phys Med Rehabil. 2013;92(11):1020-1030.

24. Cornelissen VA, Smart NA. Exercise training for blood pressure: a systematic review and meta-analysis. $J$ Am Heart Assoc. 2013;2(1): e004473.

25. Cornelissen V a, Buys R, Smart N a. Endurance exercise beneficially affects ambulatory blood pressure: a systematic review and metaanalysis. J Hypertens. 2013;31(4):639-648.

26. Macdonald HV, Johnson BT, Huedo-Medina TB, et al. Dynamic Resistance Training as Stand-Alone Antihypertensive Lifestyle Therapy: A Meta-Analysis. J Am Heart Assoc. 2016;5(10):e003231.

27. Pescatello LS, Franklin BA, Fagard R, et al. American College of Sports Medicine position stand. Exercise and hypertension. Med Sci Sports Exerc. 2004;36(3):533-553.

28. Corso LM, Macdonald HV, Johnson BT, et al. Is Concurrent Training Efficacious Antihypertensive Therapy? A Meta-analysis. Med Sci Sports Exerc. 2016;48(12):2398-2406.
29. Inder JD, Carlson DJ, Dieberg G, Mcfarlane JR, Hess NC, Smart NA. Isometric exercise training for blood pressure management: a systematic review and meta-analysis to optimize benefit. Hypertens Res. 2016;39(2):88-94.

30. Jin YZ, Yan S, Yuan WX. Effect of isometric handgrip training on resting blood pressure in adults: a meta-analysis of randomized controlled trials. J Sports Med Phys Fitness. 2017;57(1-2):154-160.

31. Ash GI, Taylor BA, Thompson PD, et al. The antihypertensive effects of aerobic versus isometric handgrip resistance exercise. J Hypertens. 2017;35(2):291-299.

32. Pescatello LS, Macdonald HV, Lamberti L, Johnson BT. Exercise for Hypertension: A Prescription Update Integrating Existing Recommendations with Emerging Research. Curr Hypertens Rep. 2015;17(11):87.

33. Eckel RH, Jakicic JM, Ard JD. 2013 AHA/ACC guideline on lifestyle management to reduce cardiovascular risk: A report of the American College of cardiology/American Heart Association task force on practice guidelines. Circulation. 2014;129(25 Suppl 1):1-46.

34. Diaz KM, Booth Iii JN, Calhoun DA, et al. Healthy Lifestyle Factors and Risk of Cardiovascular Events and Mortality in Treatment-Resistant Hypertension: The Regards Study. Hypertension. 2014;64(3):465-471.

35. Dimeo F, Pagonas N, Seibert F, Arndt R, Zidek W, Westhoff TH. Aerobic exercise reduces blood pressure in resistant hypertension. Hypertension. 2012;60(3):653-658.

36. Guimarães GV, Cruz LG, Tavares AC, Dorea EL, Fernandes-Silva MM, Bocchi EA. Effects of short-term heated water-based exercise training on systemic blood pressure in patients with resistant hypertension: a pilot study. Blood Press Monit. 2013;18(6):342-345.

37. Guimaraes GV, de Barros Cruz LG, Fernandes-Silva MM, Dorea EL, Bocchi EA. Heated water-based exercise training reduces 24-hour ambulatory blood pressure levels in resistant hypertensive patients: a randomized controlled trial (HEx trial). Int J Cardiol. 2014;172(2):434-441.

38. Cruz LG de B, Bocchi EA, Grassi G, Guimaraes GV. Neurohumoral and Endothelial Responses to Heated Water-Based Exercise in Resistant Hypertensive Patients. Circ J. 2017;81(3):339-345

39. Kenney MJ, Seals DR. Postexercise hypotension. Key features, mechanisms, and clinical significance. Hypertension. 1993;22(5):653-664.

40. Eicher JD, Maresh CM, Tsongalis GJ, Thompson PD, Pescatello LS. The additive blood pressure lowering effects of exercise intensity on post-exercise hypotension. Am Heart J. 2010;160(3):513-520.

41. Moraes MR, Bacurau RF, Simões HG, et al. Effect of 12 weeks of resistance exercise on post-exercise hypotension in stage 1 hypertensive individuals. J Hum Hypertens. 2012;26(9):533-539.

42. Brito Ade F, de Oliveira CV, Santos Mdo S, Santos Ada C. Highintensity exercise promotes postexercise hypotension greater than moderate intensity in elderly hypertensive individuals. Clin Physiol Funct Imaging. 2014;34(2):126-132.

43. Brandão Rondon MU, Alves MJ, Braga AM, et al. Postexercise blood pressure reduction in elderly hypertensive patients. $\mathrm{J} \mathrm{Am} \mathrm{Coll} \mathrm{Cardiol}$. 2002;39(4):676-682.

44. Oliveira J, Mesquita-Bastos J, Argel de Melo C, Ribeiro F. Postaerobic Exercise Blood Pressure Reduction in Very Old Persons With Hypertension. J Geriatr Phys Ther. 2016;39(1):8-13.

45. Santos LP, Moraes RS, Vieira PJ, et al. Effects of aerobic exercise intensity on ambulatory blood pressure and vascular responses in resistant hypertension: a crossover trial. J Hypertens. 2016;34(7):1317-1324.

46. Santana HA, Moreira SR, Asano RY, et al. Exercise intensity modulates nitric oxide and blood pressure responses in hypertensive older women. Aging Clin Exp Res. 2013;25(1):43-48.

47. Anunciação PG, Farinatti PT, Goessler KF, Casonatto J, Polito MD. Blood pressure and autonomic responses following isolated and combined aerobic and resistance exercise in hypertensive older women. Clin Exp Hypertens. 2016;38(8):710-714.

48. Patel HC, Hayward C, Vassiliou V, Patel K, Howard JP, di Mario C. Renal denervation for the management of resistant hypertension. Integr Blood Press Control. 2015;8:57-69.

49. Urban D, Ewen S, Ukena C, Linz D, Böhm M, Mahfoud F. Treating resistant hypertension: role of renal denervation. Integr Blood Press Control. 2013;6:119-128. 
Integrated Blood Pressure Control is an international, peer-reviewed open-access journal focusing on the integrated approach to managing hypertension and risk reduction. Treating the patient and comorbidities together with diet and lifestyle modification and optimizing healthcare resources through a multidisciplinary team approach constitute key features of the journal. This journal is indexed on American Chemical Society's Chemical Abstracts Service (CAS). The manuscript management system is completely online and includes a very quick and fair peerreview system, which is all easy to use. Visit http://www.dovepress.com/ testimonials.php to read real quotes from published authors.

Submit your manuscript here: https://www.dovepress.com/integrated-blood-pressure-control-journal 